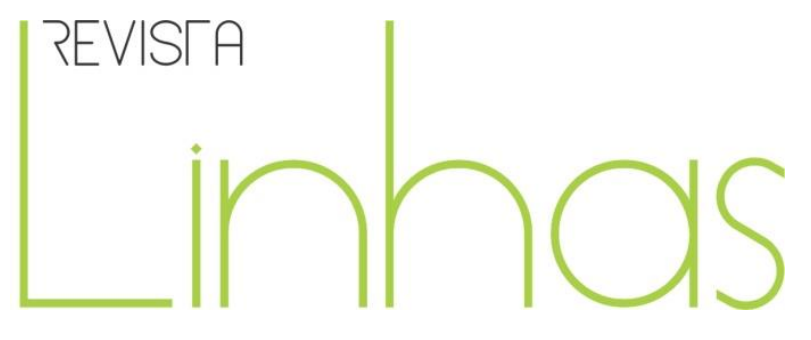

\title{
Resenha do livro "Classe dominante e educação em tempos de pandemia: uma tragédia anunciada"
}

Rodrigo Lamosa (org.)

\section{CLASSE DOMINANTE}

E EDUCAÇÃO EM TEMPOS DE PANDEMIA:

uma tragédia anunciada

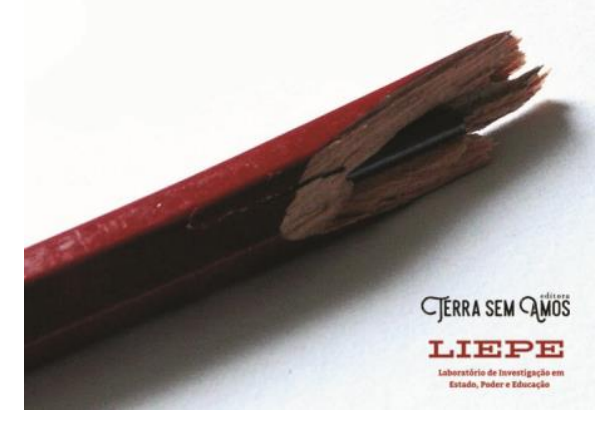

LAMOSA, Rodrigo (org.). Classe dominante e educação em tempos de pandemia: uma tragédia anunciada. Editora Terra sem Amos: Paranaíba, 2020. 140p.

Fernando Silva dos Santos

Universidade Federal de Jataí - UFJ - Jataí/GO - Brasil

fernandosantos@ufj.edu.br

\section{Para citar esta resenha:}

SANTOS, Fernando Silva dos. Resenha do livro "Classe dominante e educação em tempos de pandemia: uma tragédia anunciada”. Revista Linhas. Florianópolis, v. 22, n. 49, p. 418-426, maio/ago. 2021. 
Uma análise no calor dos acontecimentos, com profundidade teórico-metodológica e compromisso militante. Assim podemos caracterizar o livro Classe dominante e educação em tempos de pandemia: uma tragédia anunciada, organizado por Rodrigo Lamosa, professor da Universidade Federal Rural do Rio de Janeiro (UFRRJ), docente do Programa de Pós-Graduação em Educação, Contextos Contemporâneos e Demandas Populares (PPGEduc) e coordenador do Laboratório de Investigação em Estado, Poder e Educação (LIEPE).

O livro, que conta com a apresentação do professor Roberto Leher, é resultado de um ousado projeto de investigação e apresenta um conjunto de doze artigos de pesquisadores - membros do LIEPE -, que colocam em revista a atuação de intelectuais orgânicos das classes dominantes e de seus Aparelhos Privados de Hegemonia (APHs), ou, nas palavras de Leher (2020, p. 9), ações que as classes dominantes empreendem com o objetivo de manter a dominação ideopolítica para a reconfiguração do Estado e a manutenção dos "meios excepcionais de acumulação" capitalista.

Tendo como referência as categorias gramscianas de hegemonia, intelectuais coletivos e Estado ampliado ${ }^{1}$, os autores nos dão as pistas das atuações e articulações dos principais APHs que operam no Brasil, os quais, sob a influência do social-liberalismo (CASTELO, 2013) ou da emergente frente liberal ultraconservadora (COLOMBO, 2018), alçaram o bolsonarismo - ponta de lança de um protofascismo à brasileira - ao bloco do poder e, ainda que se expressem sob uma aparente oposição devido a concepções de mundo distintas, protagonizaram ações bastante funcionais, como a adoção de instrumentos para destruição de direitos, especialmente, os relacionados à educação pública brasileira.

Lamosa, além de organizador do volume, é responsável pelo capítulo inicial, que trata dessa aparente disputa entre frações das classes dominantes, frações atuantes na

\footnotetext{
1 Em Gramsci (2001), a hegemonia é a capacidade de um grupo social unificar, em torno de seu projeto político, um bloco mais amplo, não homogêneo e marcado por contradições de classe. O grupo ou classe que lidera esse bloco é hegemônico porque consegue ir além de seus interesses econômicos. Os intelectuais são os prepostos do grupo dominante para o exercício das funções subalternas da hegemonia social e do governo político, por meio do consenso espontâneo dado pelas grandes massas da população à orientação fixada pelo grupo fundamental dominante. Estado ampliado é o conjunto formado pela sociedade civil (isto é, o conjunto de organismos designados vulgarmente como privados) e pela sociedade política.
} 
definição das políticas públicas para a educação brasileira: os movimentos Todos pela Educação (TPE) e o Escola Sem Partido (ESP). O livro conta ainda com artigos de Renata Spadetti Tuão, Fabrício Fonseca da Silva, Lívia Herdade, Amanda Rodrigues, Ramon Mendes da Costa Magalhães, Amanda de Oliveira Pereira, Carlos Maurício Franklin Lapa, Pedro Henrique Dias Siqueira, Bárbara Evangelista e Luiza Rabelo Colombo, professores e militantes da educação e integrados ao LIEPE.

A coletânea investiga a atuação de movimentos diretamente vinculados à educação, como o TPE (LAMOSA, 2020b; SILVA, 2020; HERDADE, 2020; RODRIGUES, 2020; PEREIRA, 2020; LAPA, 2020; SIQUEIRA, 2020; MAGALHÃES, 2020b) e o ESP (LAMOSA, 2020b; COLOMBO, 2020) , mas também nos apresenta um importante "guia" com as práticas, ações, articulações de grupos privados como o Movimento Brasil Competitivo (SILVA, 2020), Fundação Roberto Marinho (RODRIGUES, 2020; PEREIRA, 2020; LAPA, 2020), Instituto Ayrton Senna (LAMOSA, 2020b; MAGALHÃES, 2020a; PEREIRA, 2020), Fundação Itaú Social (HERDADE, 2020; PEREIRA, 2020), Fundação Bradesco (HERDADE, 2020; LAPA, 2020), Fundação Lemann (SILVA, 2020; HERDADE, 2020; PEREIRA, 2020; SIQUEIRA, 2020) e a Confederação Nacional da Indústria (EVANGELISTA, 2020). Os estudos apresentados pelo coletivo do LIEPE ainda apresentam a atuação do braço do empreendedorismo estatal com o Serviço Brasileiro de Apoio às Micro e Pequenas Empresas (SEBRAE) e as recomendações do Banco Interamericano de Desenvolvimento (BID).

Esse verdadeiro congiérie social ${ }^{2}$, como apontava Fernandes (1987), moldou a atuação do Estado e de suas instituições, seja por meio de assessoramento, orientações, recomendações, seja também pela elaboração e difusão de ações que aprofundam a contrarreforma do aparelho estatal e recolocam, na ordem do dia, novas formas de acumulação de capitais, aprofundadas em meio à pandemia global ${ }^{3}$ da SARS-COV2 (COVID19).

\footnotetext{
${ }^{2}$ Para Florestan Fernandes, o que unia os vários setores ou frações de classe não eram necessariamente interesses comuns, mas a maneira pela qual tenderiam a polarizar certas utopias.

${ }^{3}$ Em 11 de março de 2020, a COVID-19 foi caracterizada pela OMS como uma pandemia. O termo "pandemia" se refere à distribuição geográfica de uma doença e não à sua gravidade. A designação reconhece que, no momento, existem surtos de COVID-19 em vários países e regiões do mundo (OPAS, s/d).
} 
Em tempos de pandemia, as frações da classe dominante têm atuado na educação - em todos os níveis e modalidades - atribuindo peso fundamental ao estímulo para o uso das chamadas Tecnologias de Informação e Comunicação (RODRIGUES, 2020), em colaboração com a contrarreforma do arcabouço legal, que se materializa no estrangulamento dos recursos públicos para a educação e nas mudanças da Lei de Diretrizes e Base (LDB), apontado por Colombo (2020); na aprovação e implementação da Base Nacional Comum Curricular (BNCC), destacadas por Lamosa (2020b), Rodrigues (2020), Magalhães (2020a; 2020b), Pereira (2020) e Lapa (2020); e no chamado Novo Ensino Médio, destacados por Leher (2020), Lamosa (2020b), Silva (2020), Rodrigues (2020), Magalhães (2020a; 2020b), Lapa (2020) e Colombo (2020).

A tragédia anunciada pela ostensiva presença das frações dominantes, por meio de seus movimentos, institutos e fundações, visa, sobretudo, à conformação das subjetividades das parcelas subalternas, um projeto planejado e executado para que um “novo tipo de trabalhador" (MAGALHÃES, 2020a; 2020b), com habilidades e competências (LAPA, 2020) para a adaptabilidade (LAMOSA, 2020b; RODRIGUES, 2020) e a cooperação, formadas por capacidades socioemocionais (LAMOSA, 2020b; RODRIGUES, 2020; MAGALHÃES, 2020a; PEREIRA, 2020, COLOMBO, 2020) e pelas demandas de itinerários ou percursos formativos (RODRIGUES, 2020; PEREIRA, 2020), ajuste-se a expectativas e projetos de vida (LAMOSA, 2020b; MAGALHÃES, 2020a) da classe trabalhadora, cada vez mais distantes da realidade concreta da luta de classes e cada vez mais apropriadas às “exigências dos atuais padrões de reprodução do capital” (LAMOSA, 2020b, p. 18).

A pandemia acelerou esse processo e potencializou a aquisição e utilização de produtos e serviços educacionais de interface computacional, voltados tanto para a educação básica quanto para o ensino superior, que sejam capazes de realizar uma transição para um projeto que tem na educação digital um importante instrumento para forjar as bases do que Lúcia Neves (2010) chamou de nova pedagogia da hegemonia. Essas iniciativas foram fortalecidas ao longo dos primeiros meses da emergência sanitária, especialmente no Brasil. Como assinala Lamosa (idem, p. 20), com o agravamento da situação pandêmica, muitas prefeituras e estados, assim como instituições escolares, incluindo as universidades públicas, passaram a adotar medidas emergenciais e muitas “dão como certa a transição para um ensino híbrido”, no qual “coexistam ensino presencial 
e a educação online". Corroborando a afirmação, Pró-reitores de graduação de duas das principais instituições de ensino superior pública no Brasil, a Universidade de São Paulo (USP) e Universidade de Campinas (UNICAMP), comunicaram que já avaliam a manutenção da Educação a Distância (EAD) "para parte dos conteúdos de graduação mesmo quando as aulas presenciais voltarem" (PINHO, 2021, p.B6). Notícias como essa ratificam a importância - e emergência - de estudos dessa magnitude, para que possamos compreender a dominação de amplo espectro que frações burguesas estão empreendendo no Brasil.

A articulação dos capítulos, a profundidade teórico-metodológica e o traço refinado de uma escrita acadêmica que tem lado são elementos importantes da coletânea, que tem como objetivo a renovação das forças militantes na luta em defesa da imprescindível educação pública. O importante inventário apresentado ao longo de todo o livro evidencia as formas de atuação em rede das frações dominantes, as estratégias, os seus intelectuais coletivos, a atuação em sintonia com os organismos multilaterais (OM), a articulação de seus projetos e programas voltados para a educação, os quais desempenham importante papel na conformação de consensos sobre a nova feição do Estado.

O pacto para o novo padrão de acumulação, baseado nas novas tecnologias, na coalizão público-privada, na destruição de direitos sociais (vide reformas trabalhista e previdenciária) e na reestruturação produtiva, demanda o aprofundamento da contrarreforma do aparelho estatal. E é esse novo padrão de acumulação, o chamado capitalismo de plataforma4, que está em curso; e "a pandemia do novo coronavírus acelerou as tendências que já estavam colocadas pela nova fase do capitalismo" (SILVA, 2020, p. 44).

É nesse cenário que a pandemia se transformou no laboratório para o ensino remoto como experiência das novas estratégias da dominação burguesa na educação. Uma dominação que se fortalece e amplia seus tentáculos em muitas frentes. Dentre essas frentes, uma das mais importantes para as frações burguesas é a de tornar o atual Ensino Remoto Emergencial (ERE) em ferramenta permanente do processo de ensino-

\footnotetext{
${ }^{4}$ Nick Srnicek (2018) define o novo estágio de acumulação da economia como capitalismo de plataforma, ou economia digital, que consiste num novo modelo de negócios, que dependem das tecnologias de informação e da comunicação via internet.
} 
aprendizagem, para forjar, na opinião pública, o consenso sobre o direito à aprendizagem, fortalecendo a ideia de que, com a pandemia, o uso de ferramentas de tecnologia da informação e comunicação se mostra inevitável e irreversível, ou seja, modela-se, assim, uma solução pragmática que tem a EAD como sua principal aliada, o que leva também ao fortalecimento das experiências de ensino domiciliar (COLOMBO, 2020) e do chamado homeschooling (PEREIRA, 2020; COLOMBO, 2020).

Outra importante frente da investida das frações burguesas na educação se vincula à formação de professores, de gestores e de trabalhadores da educação, para a criação de um trabalhador de novo tipo, mais flexível, conformado pela concepção e cultura empreendedora, que se baseiam em determinadas habilidades e competências socioemocionais, para preparar professores e gestores de instituições públicas para a transição da modalidade presencial para a modalidade online. A intenção de naturalizar novas ferramentas digitais como parte de uma realidade inexorável no processo educacional segue a mesma lógica da naturalização de instrumentos externos de avaliação em ampla escala, promovidos pelos $\mathrm{OM}$, há pelo menos três décadas, junto às secretarias de educação municipais, estaduais e demais órgãos administrativos das administrações públicas. A pandemia fortaleceu ainda mais o elo das parcerias público-privadas já bastante influenciadas pela lógica do gerencialismo difundido pela ideologia burguesa na implementação de novas políticas públicas para a educação, gerando uma pressão para a normatização das medidas "emergenciais" que foram adotadas durante a emergência sanitária.

Em relação aos alunos (e também em relação aos familiares), a expectativa das APHs é a formação do indivíduo empreendedor, capturado pela subjetividade das linguagens da inovação que forjam "personalidades adequadas às necessidades do mercado de trabalho e da vida social, marcada por uma instabilidade sócio-econômicoemocional fruto da própria estrutura do capital” (MAGALHÃES, 2020a, p. 70). Para esses indivíduos, restaria a adaptação a um projeto de vida com vistas à formação de aspectos físicos, cognitivos e socioemocionais, elementos presentes em todos os documentos das políticas educacionais recentes, que expressam o desejo empresarial de definir um tipo de trabalhador adaptado às exigências dos atuais padrões de reprodução do capital (LAMOSA, 2020b, p. 19). 
Dentro do cenário devastador da crise cíclica do modo de produção é que as frações burguesas parecem ter encontrado, nessa pandemia de proporções catastróficas, “oportunidades5" de negócios, que, de tão nefastas, demonstram a voracidade do capital e a impossibilidade da manutenção desse sociometabolismo que tem caráter irreformável e incorrigível, como nos alerta Meszáros (2012), desnudando, ao mesmo tempo, a insanidade burguesa em estado puro.

É preciso mais do que nunca rompermos as ilusões do consenso que apassivou a classe trabalhadora, colocando nossas palavras de ordem, como no poema de Brecht, em total desordem.

O livro coordenado por Rodrigo Lamosa (LAMOSA, 2020a) nos dá elementos valiosos e fundamentais para avançarmos na reflexão sobre os aparelhos privados de hegemonia da classe dominante e sobre suas formas de dominação ideopolítica. A par desse importante inventário da atuação das frações burguesas no aparato estatal e na educação, é fundamental que compreendamos que estamos diante da véspera da batalha, por isso devemos preparar nossos quadros, estudar nosso plano de lutas e nos aprontarmos para o dia antes da queda de nossos inimigos.

\section{Referências}

CASTELO, Rodrigo. O social-liberalismo: auge e crise da supremacia burguesa na era neoliberal. São Paulo: Expressão Popular, 2013.

COLOMBO, Luiza Rabelo. A frente liberal-ultraconservador no Brasil: reflexões sobre e para além do “movimento Escola Sem Partido". 2018. Dissertação (mestrado em Educação) - UFRRJ/Programa de Pós-Graduação em Educação, Contextos Contemporâneos e Demandas Populares. Disponível em: https://liepe.amandy.com.br/assets/data/files/A_frente_liberal ultraconservadora_no_Brasil_Luiza_Colombo_2018.pdf Acesso em: 19 abr. 2021.

COLOMBO, Luíza Rabelo. Educação domiciliar a pretexto do "ensino remoto emergencial: o que dizem as igrejas evangélicas? In: LAMOSA, Rodrigo (Org). Classe dominante e educação em tempos de pandemia: uma tragédia anunciada. Editora Terra sem Amos: Parnaíba, 2020, p. 125-137.

\footnotetext{
${ }^{5}$ Conforme Guimarães (2020), Jorge Paulo Lemann teria tido melhores oportunidade de negócios em meio a
} crises. 
EVANGELISTA, Bárbara. A Confederação Nacional da Indústria e suas ações em meio à pandemia de Covid-19 no Brasil. In: LAMOSA, Rodrigo (Org). Classe dominante e educação em tempos de pandemia: uma tragédia anunciada. Editora Terra sem Amos: Parnaíba, 2020, p. 107-114.

FERNANDES, Florestan. A Revolução Burguesa no Brasil. 1987.

GRAMSCl, Antonio. Cadernos do cárcere, vol. 2. 2a ed. - Rio de Janeiro: Civilização Brasileira, 2001.

GUIMARÃES, Fernanda. Melhores negócios que fiz foram em crises, diz Jorge Paulo Lemann. O Estado de S. Paulo. São Paulo, 16 abr. 2020. Economia. Disponível em: https://economia.estadao.com.br/noticias/geral,melhores-negocios-que-fiz-foram-emcrises-diz-jorge-paulo-lemann,70003273375. Acesso em 19 abr. 2021.

HERDADE, Lívia. Todos pela educação? Classe dominante, poder e hegemonia em tempos de pandemia. In: LAMOSA, Rodrigo (Org). Classe dominante e educação em tempos de pandemia: uma tragédia anunciada. Editora Terra sem Amos: Parnaíba, 2020, p. 47-54.

LAMOSA, Rodrigo (Org). Classe dominante e educação em tempos de pandemia: uma tragédia anunciada. Editora Terra sem Amos: Parnaíba, $2020 a$.

LAMOSA, Rodrigo. As frentes de ação da classe dominante na educação: entre o todos pela educação e a ideologia escola sem partido. In: LAMOSA, Rodrigo (Org). Classe dominante e educação em tempos de pandemia: uma tragédia anunciada. Editora Terra sem Amos: Parnaíba, 2020b, p. 11-22.

LAPA, Carlos Maurício Franklin. Fundação Bradesco: hegemonia e o "novo normal” da educação à distância. In: LAMOSA, Rodrigo (Org). Classe dominante e educação em tempos de pandemia: uma tragédia anunciada. Editora Terra sem Amos: Parnaíba, 2020, p. 85-96.

LEHER, Roberto. Compreender o que fazem os setores dominantes quando dominam para construir alternativas para a educação pública, laica e unitária (Apresentação). In: LAMOSA, Rodrigo (Org). Classe dominante e educação em tempos de pandemia: uma tragédia anunciada. Editora Terra sem Amos: Parnaíba, 2020, p. 05-10.

MAGALHÃES, Ramon Mendes da Costa. O Instituto Ayrton Senna e as competências socioemocionais em tempos de pandemia Covid-19. In: LAMOSA, Rodrigo (Org). Classe dominante e educação em tempos de pandemia: uma tragédia anunciada. Editora Terra sem Amos: Parnaíba, 2020a, p. 63-74.

MAGALHÃES, Ramon Mendes da Costa. O Sebrae e o empreendedorismo em tempos de pandemia Covid-19. In: LAMOSA, Rodrigo (Org). Classe dominante e educação em tempos de pandemia: uma tragédia anunciada. Editora Terra sem Amos: Parnaíba, 2020b, p. 115-124. 
MÉSZÁROS, István. Educação para além do capital. 2.ed. São Paulo: Boitempo, 2012.

NEVES, Lúcia Maria Wanderley (org.). Direita para o social e esquerda para o capital: intelectuais da nova pedagogia da hegemonia no Brasil. São Paulo: Xamã, 2010.

OPAS - ORGANIZAÇÃO PAN-AMERICANA DE SAÚDE, Histórico da Pandemia de COVID-19. Disponível em: https://www.paho.org/pt/covid19/historico-da-pandemia-covid-19. Acesso em 19 abr. 2021.

PEREIRA, Amanda de Oliveira. A atuação da Fundação Itaú Social no campo educacional em meio à pandemia da Covid-19. In: LAMOSA, Rodrigo (Org). Classe dominante e educação em tempos de pandemia: uma tragédia anunciada. Editora Terra sem Amos: Parnaíba, 2020, p. 75-84.

PINHO, Angela. USP e Unicamp preveem manter ensino a distância em parte dos cursos após pandemia. Folha de São Paulo, São Paulo, 3 abr. 2021. Cotidiano. p. B6.

RODRIGUES, Amanda. A Fundação Roberto Marinho e a crise sanitária pavimentando o caminho para a expansão do ensino remoto nas escolas públicas. In: LAMOSA, Rodrigo (Org). Classe dominante e educação em tempos de pandemia: uma tragédia anunciada. Editora Terra sem Amos: Parnaíba, 2020, p. 55-62.

SILVA, Fabrício Fonseca da. Propostas e ações do Movimento Brasil Competitivo para setor público, economia e educação no pós-pandemia. In: LAMOSA, Rodrigo (Org). Classe dominante e educação em tempos de pandemia: uma tragédia anunciada. Editora Terra sem Amos: Parnaíba, 2020, p. 35-46.

SIQUEIRA, Pedro Henrique Dias. A Fundação Lemann: uma análise sobre sua atuação na Pandemia da COVID-19. In: LAMOSA, Rodrigo (Org). Classe dominante e educação em tempos de pandemia: uma tragédia anunciada. Editora Terra sem Amos: Parnaíba, 2020, p. 97-106.

SRNICEK, Nick. Capitalismo de plataforma. Ciudad Autónoma de Bueno Aires: Caja Negra, 2018.

Recebido em: 13/02/2021 Aprovado em: 28/03/2021

Universidade do Estado de Santa Catarina - UDESC Programa de Pós-Graduação em Educação - PPGE Revista Linhas

Volume 22 - Número 49 - Ano 2021 revistalinhas@gmail.com 